\title{
Clinical evaluation of accelerated cardiac cine imaging using iterative k-t-sparse SENSE
}

\author{
Bradley D Allen ${ }^{1 *}$, Maria Carr ${ }^{1}$, Michael O Zenge ${ }^{2}$, Michaela Schmidt ${ }^{2}$, Mariappan S Nadar ${ }^{3}$, Bruce S Spottiswoode ${ }^{4}$, \\ Jeremy D Collins ${ }^{1}$, James C Carr ${ }^{1}$ \\ From 17th Annual SCMR Scientific Sessions \\ New Orleans, LA, USA. 16-19 January 2014
}

\section{Background}

We sought to quantitatively and qualitatively evaluate a clinical implementation of accelerated MR acquisitions using iterative segmented k-t-sparse Cartesian SENSE balanced steady-state free-precession (SSFP) cinegraphic imaging.

\section{Methods}

IRB approval was obtained. Twenty patients (age: $54.8 \pm$ 14 years, $M: F=15: 5)$ undergoing non-emergent $C M R$ assessment for myocardial pathology were consecutively recruited. Nine healthy volunteers (age: $44.3 \pm 14$ years, $\mathrm{M}: \mathrm{F}=6: 3$ ) were also imaged. CMR was performed at 1.5T (MAGNETOM Aera, Siemens Healthcare, Erlangen, Germany). The examination included acquisition of standard segmented SSFP (iPAT2) (GRAPPA accel factor 2 , TR $\left.40 \mathrm{msec}, 2.1 \times 2.1 \times 10 \mathrm{~mm}^{3}\right)$ cine and two accelerated segmented SSFP acquisitions (TPAT accel factor 4, TR $37.7 \mathrm{msec}, 2.1 \times 2.1 \times 6 \mathrm{~mm}^{3}$ ), one with an investigational prototype inline iterative $\mathrm{k}$-t-sparse SENSE reconstruction with L1 regularization along one spatial and temporal dimension (TPAT4 $4_{\mathrm{i}}$ ) (1)and the other with conventional SENSE reconstruction (TPAT4). Each technique was used to acquire a three(3Ch), four-chamber (4Ch), and short axis (SA) series in identical slice positions (Figure 1), with SA coverage of the entire left ventricle (LV) with $10 \mathrm{~mm}$ interslice gaps. Individual slice scan times were recorded. Quantitative LV functional analysis was performed. A reviewer blinded to acquisition type scored images for overall image quality, noise, and artifacts using a 5-point Likert scale. Continuous variables were compared between groups using a paired t-test, and ordinal variables were compared using a Wilcoxon signed-rank test.

\section{Results}

In a combined analysis of patients and volunteers, there was no significant difference between LV ejection fraction between iPAT2 and TPAT $4_{\mathrm{i}}(\mathrm{p}=0.48)$ or TPAT4 $(\mathrm{p}=0.34)$. The iPAT2 technique found marginally lower end-diastolic volume $(159 \pm 54 \mathrm{ml}$ vs. $169 \pm 54 \mathrm{ml}, \mathrm{p}=$ $0.01)$, end-systolic volume $(75 \pm 33 \mathrm{ml}$ vs. $80 \pm 31 \mathrm{ml}$, $\mathrm{p}=0.04)$, stroke volume $(80 \pm 35 \mathrm{ml}$ vs. $89 \pm 31 \mathrm{ml}$, $\mathrm{p}=0.03)$ compared to TPAT4 $4_{\mathrm{i}}$. Single-slice scan times in both TPAT $_{4}(3.29 \pm 0.6 \mathrm{sec})$ and TPAT4 $(3.0 \pm 0.6$ $\mathrm{sec})$ acquisitions were significantly shorter relative to iPAT2 $(8.4 \pm 1.7$ sec, p $<0.001$ for both $)$. Qualitative review showed significantly higher image quality and lower noise using both iPAT2 and TPAT $4_{i}$ acquisitions relative to TPAT4 (quality: $\mathrm{p}<0.001$, noise: $\mathrm{p}<0.001$ ). The iPAT2 acquisition was scored higher than TPAT4 $4_{\mathrm{i}}$ in quality $(4.8 \pm 0.4$ vs. $4.6 \pm 0.6, \mathrm{p}=0.005)$, noise $(4.9 \pm 0.3$ vs. $4.6 \pm 0.6, \mathrm{p}<0.001)$, and artifact $(4.8 \pm 0.4$ vs. $4.6 \pm 0.6, p=0.04)$, although the magnitude of difference is relatively small. (Figure 2 )

\section{Conclusions}

Acceleration using iterative k-t-sparse SENSE techniques can be successfully applied in CMR to reduce scan times by $>50 \%$ while maintaining diagnostic image quality and quantitative accuracy in LV systolic function assessment.

${ }^{1}$ Radiology, Northwestern University, Chicago, Illinois, USA

Full list of author information is available at the end of the article 


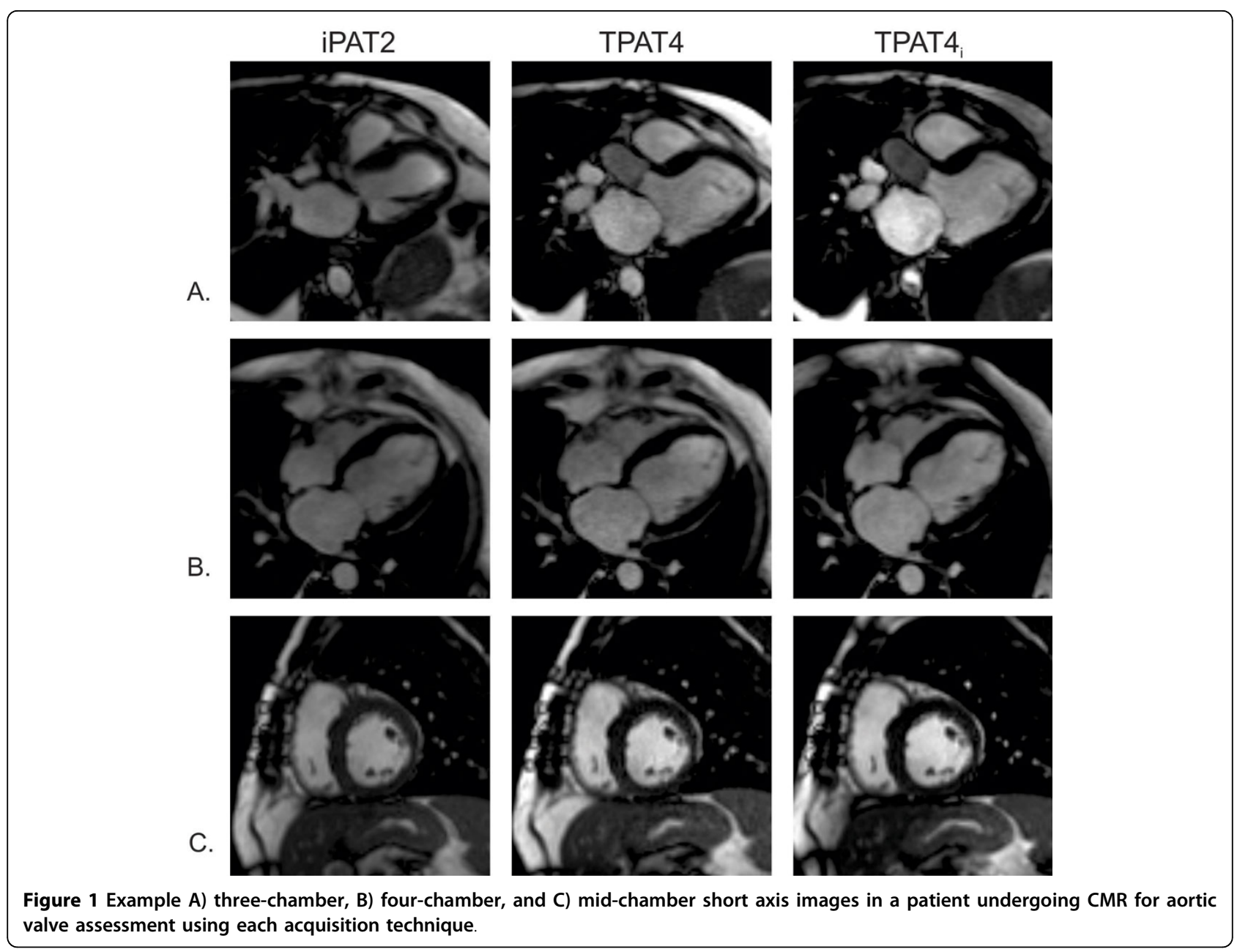

Figure 1 Example A) three-chamber, B) four-chamber, and C) mid-chamber short axis images in a patient undergoing CMR for aortic valve assessment using each acquisition technique.

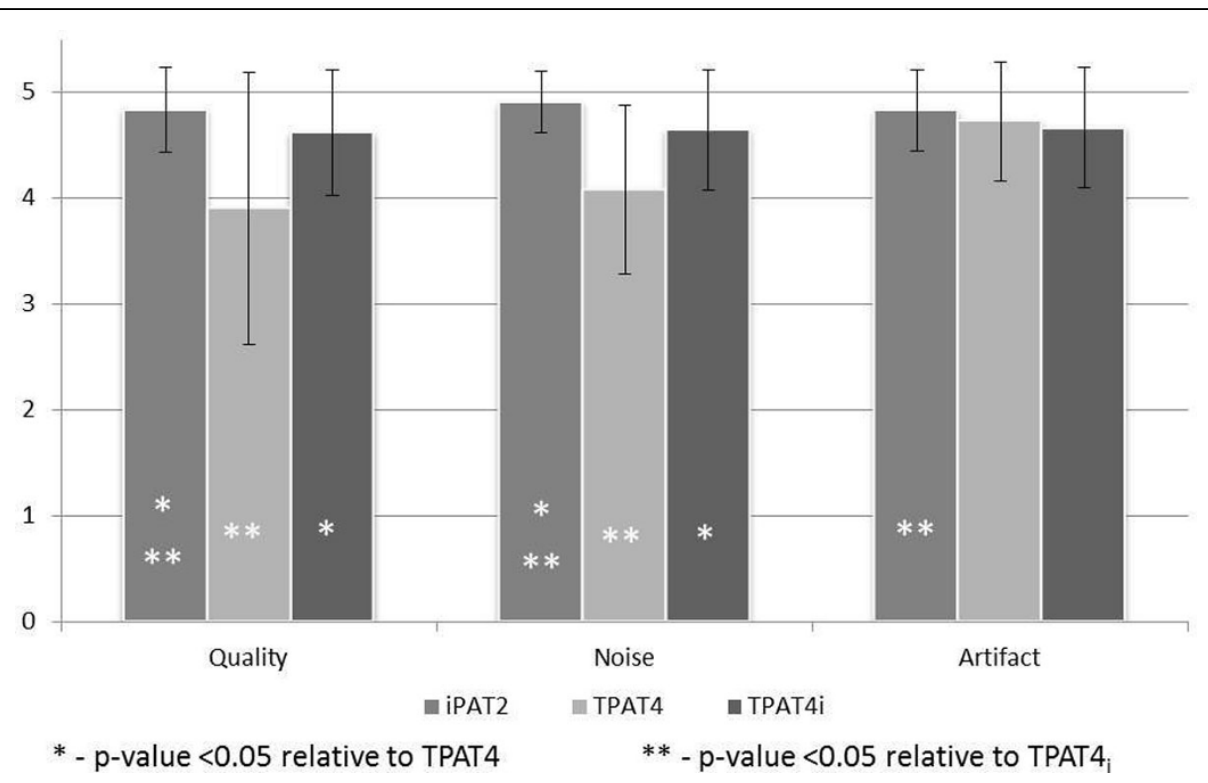

Figure 2 Qualitative scoring in the combined cohort of patients and volunteers. 


\section{Authors' details}

${ }^{1}$ Radiology, Northwestern University, Chicago, Illinois, USA. ${ }^{2}$ Siemens AG Healthcare Sector, Erlangen, Germany. ${ }^{3}$ Siemens Corporate Technology, Princeton, New Jersey, USA. ${ }^{4}$ Siemens Healthcare USA, Inc., Chicago, Illinois, USA.

Published: 16 January 2014

\section{Reference}

1. Liu J, et al: ISMRM 20th Annual Meeting Melbourne, Australia; 2012, 4249.

doi:10.1186/1532-429X-16-S1-W13

Cite this article as: Allen et al: Clinical evaluation of accelerated cardiac cine imaging using iterative k-t-sparse SENSE. Journal of Cardiovascular Magnetic Resonance 2014 16(Suppl 1):W13.

Submit your next manuscript to BioMed Central and take full advantage of:

- Convenient online submission

- Thorough peer review

- No space constraints or color figure charges

- Immediate publication on acceptance

- Inclusion in PubMed, CAS, Scopus and Google Scholar

- Research which is freely available for redistribution

Submit your manuscript at www.biomedcentral.com/submit
() Biomed Central 